\title{
Experimental Study on Water Erosion Resistance Characteristics to Steam Turbine Blade Material
}

\author{
Zheyuan Zhang ${ }^{1}$, Yonghui Xie ${ }^{1, *}$, and Di Zhang ${ }^{2}$ \\ ${ }^{1}$ School of Energy and Power Engineering, Xi'an Jiaotong University, Xi'an, Shaanxi Province, 710049, P. R. China. \\ ${ }^{2}$ Key Laboratory of Thermal Fluid Science and Engineering of Ministry of Education, School of Energy and Power Engineering, Xi' an \\ Jiaotong University, Xi'an, Shaanxi Province, 710049, P. R. China.
}

\begin{abstract}
An experimental system to assess the water erosion resistance of the steam turbine blade material was built. It can conduct the test of the blade material water erosion resistance characteristic with different water jet diameter and different impact velocity. The experimental investigation of the water erosion resistance characteristics of the blade materials with different surface treatment processes are carried out. By weighing the specimens of each stage, the curves of mass loss with time are obtained. The 2D metal micrograph, 3D surface topography and cross section pit curves are achieved with a laser 3D microscopy. The results reveal the characteristics of the specimens at all stages during the experiment. A method was proposed that the water erosion resistance characteristic can be evaluated by the volume loss based on the pit cross section size, which solves the problem that it's difficult to compare the masses with different material densities or coating densities. The experimental study in this paper has great value for the turbine blade material selection in the steam stages and surface protection technology.
\end{abstract}

\section{Introduction}

The last-stage blades of modern high-power ultrasupercritical and nuclear turbine are longer than before, which leads to a great increase in the circumferential velocity of the blade shroud. Water erosion areas are basically located on the blade inlet edge top, and the impact velocity of water drops greatly increase as a result of the high circumferential velocity, which leads to the larger impact stress and reduction of the fatigue life. Consequently, the operation of turbine plant is seriously threatened.

Much experimental study on water erosion has been conducted since 1920s, and several researchers tried to build accurate and stable experimental analysis systems in order to establish the standard test process. Scholars agree that water erosion experimental evaluation is important in the process of blade design and material selection. Water erosion resistance test on real turbine blade is expensive, so the key parameters are selected to simplify the experimental system in order to complete the analysis system. The serious influence caused by the high-velocity drop impact was proposed by Honegger [1], and later an experiment was carried out on account of the turbine blade water erosion accidents. During the experiment, the turbine blade material was impacted by the water jet with a velocity of $200 \mathrm{~m} / \mathrm{s}$. A large-scale analysis system for rain erosion was established by German Dornier Company [2], and many different working conditions could be analysed. Ripken [3] also established a simple vertically arranged water erosion analysis system. With the increase of turbine power, the last-stage blade is longer, and a number of analysis systems were established, such as the experimental systems in British Electric Company, CA Parsons and British Central Electricity Authority [4]. In 1970, a small analysis system with high-velocity jet was established by NASA to conduct experimental analysis on aluminium 1100-0 and stainless steel 316[5]. In addition to the rotary experimental systems, the experimental system on single high-velocity jet impact was built as well. The first single jet impact device was built by Bowden [6]. It was founded that the erosion area consisted of pits and it was surrounded by some broken area caused by the high shear force. In addition, a measuring device was set up to measure the pressure distribution inside the water drop by Rochester and Brunton [7]. Hoff [2] developed a small-scale experimental facility to study energy conversion problem during the impact of the pendulum. D.C.Jenkins [8] established an experimental system for the study of the impact between a liquid drop and a surface moving at high speed. Toshiyuki [9] et al developed a device to study the impact of high-speed steam-droplet spray on solid surface.

These experimental systems show that water erosion depends on various experimental conditions and material characteristic parameters. For the majority of the materials with good resistance to water erosion, the water erosion begins from an incubation period with little mass loss, then the damage expands until it reaches a maximum, after which the water erosion rate decreases until it is stable.

* Corresponding author: yhxie@mail.xjtu.edu.cn 
A rotary water erosion experimental system for turbine wet steam stage blade material was designed and built based on the actual operating conditions of turbine blade and the research on water erosion in the recent years. Since the average experiment time reaches to at least dozens of hours, it is very difficult to guarantee the same parameters completely every time. The system can analyse at most 24 specimens simultaneously, so the variables can be controlled as much as possible. The experimental analysis for specimens of base material and those protected by two different surface protection treatments was conducted in this paper. Some significant results were obtained including the water erosion characteristics of all the specimens, the sort of water erosion resistance ability of different specimens and two important parameters influencing water erosion.

\section{Experimental system}

An experiment platform is designed for the research on water erosion resistance characteristics of wet steam stage blades, and the water erosion resistance performances of base material and surface-treated material are obtained directly. It provides evaluation criteria for the water erosion of turbine wet steam stage blade and basic data for water erosion resistance treatments.

The shaft velocity ranges from 0 to $9000 \mathrm{r} / \mathrm{min}$, and the drop diameter ranges from $0.1 \mathrm{~mm}$ to $0.3 \mathrm{~mm}$ while the maximum impact velocity is above $650 \mathrm{~m} / \mathrm{s}$. The experiment platform consists of a DC motor, a gear increaser, an ultra-high pressure pump, a vacuum pump, an experiment box, a lube oil system and a control system. The schematic diagram of the experiment platform is shown in Fig. 1.

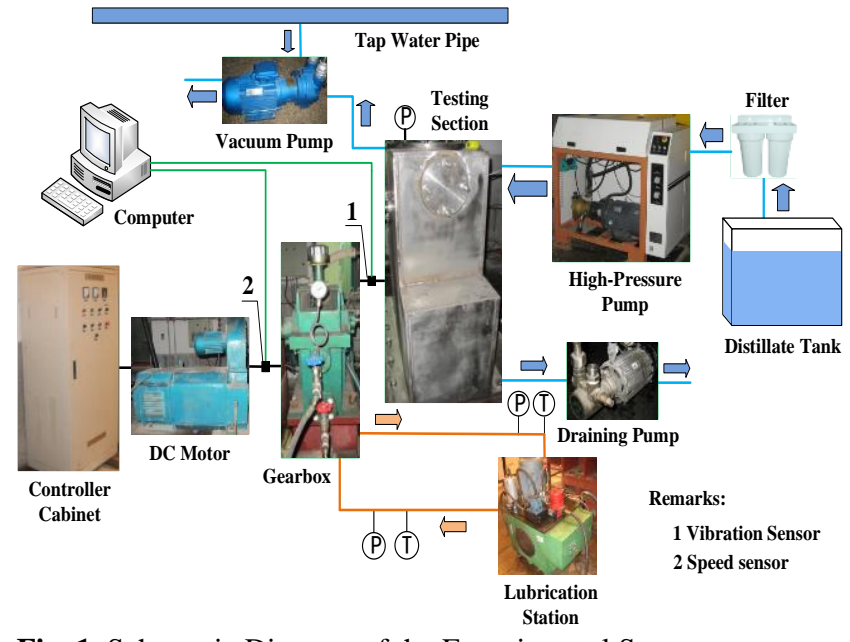

Fig. 1. Schematic Diagram of the Experimental System

The DC motor is controlled by the motor control cabinet and the motor gets connected to the gearbox. The coupling is applied to connect the output end of gearbox and shaft, and there is roulette on the shaft, which can rotate in a high velocity with specimens. There is also a sealing shell and a nozzle outside. The nozzle is used to lead the water from the pump outside the shell, and its position greatly agrees with the specimen position. There is a connection between the shell and the vacuum pump, and a drain pump is located at the bottom of the cylinder.

The high-pressure pump nozzle, shaft and roulette are shown in Fig. 2.

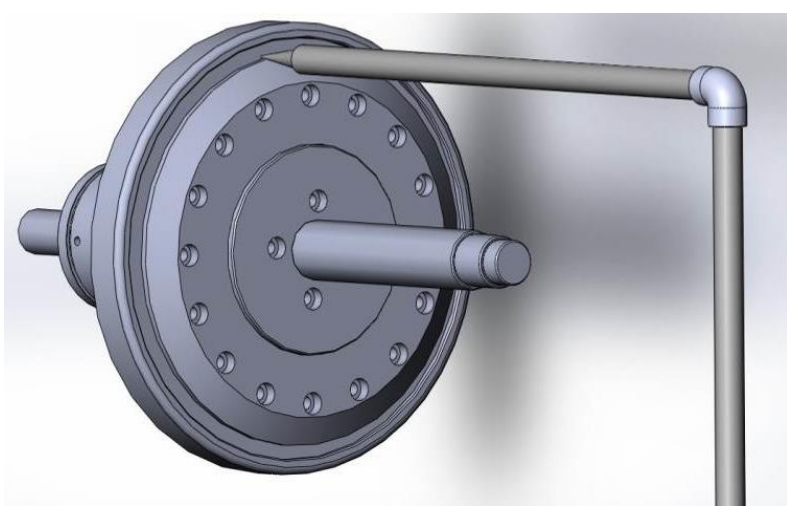

Fig. 2 High-pressure pump nozzle, shaft and roulette

The ultra-high pressure pump and generator are shown in Fig. 3 and Fig. 4. The main parameters of the ultra-high pressure pump are described as follows: the maximum of jet outlet pressure is $300 \mathrm{MPa}$ and the maximum working pressure can reach $240 \sim 260 \mathrm{MPa}$. Because the pressure is adjustable and measurable, the jet velocity can fully simulate the real velocity of wet steam drops.

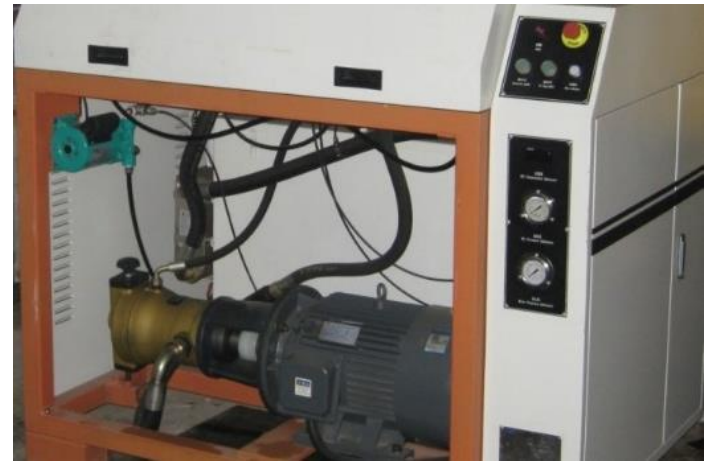

Fig. 3 Ultra-high pressure pump

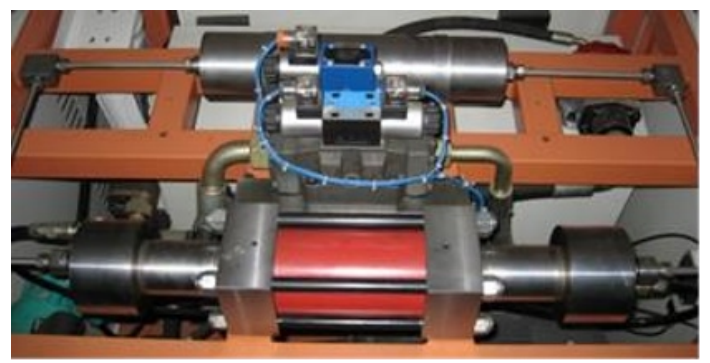

Fig. 4 Ultra-high pressure generator

The diameter of the throttle nozzle is a key part and it must be adjustable. The jet injector and throttle nozzles with different diameters are shown in Fig. 5. The jet injector is fixed on the shell and the nozzle extending into the shell inside faces the specimen surfaces.

It is necessary to stop the machine and observe the specimen surface at intervals during the experiment. Initially the interval time is short, and once the water erosion phenomenon occurs, the surface morphology 
characteristics should be recorded immediately. The weighing is conducted after the preheating of the precise balance and the cleaning of the specimen surface. The data record is carried out when it remains stable.

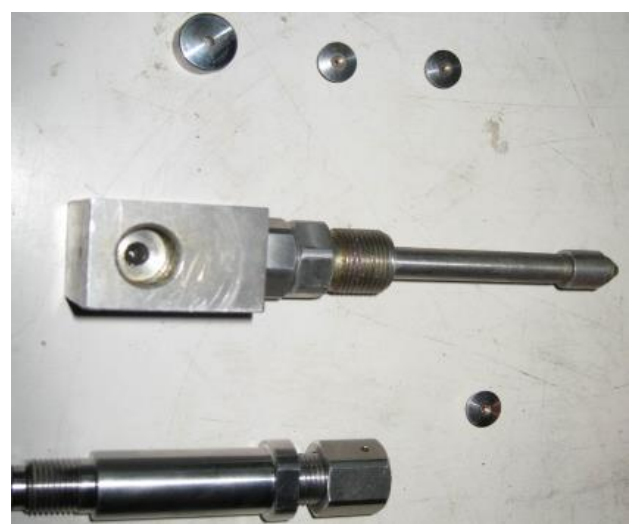

Fig. 5 Jet injector and nozzles with different diameters

\section{Results and discussion}

The water erosion analysis for three kinds of specimens is carried out on the rotary experiment platform. The specimens are the base material specimen with simple heat treatment, high frequency quenching material specimen with hardened surface and stellite-welded specimen respectively. The water erosion photos at different moments for testing material specimen are shown in Fig. 6
$3 \mathbf{h}$

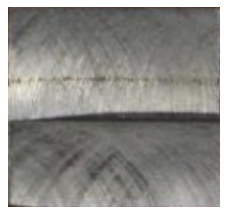

$10 \mathrm{~h}$

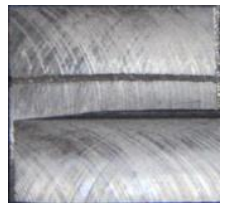

42h

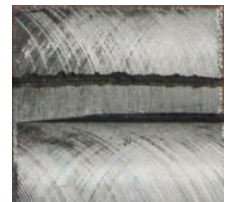

Base material
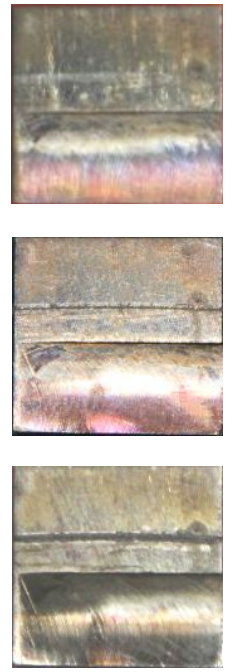

High-frequency quenching
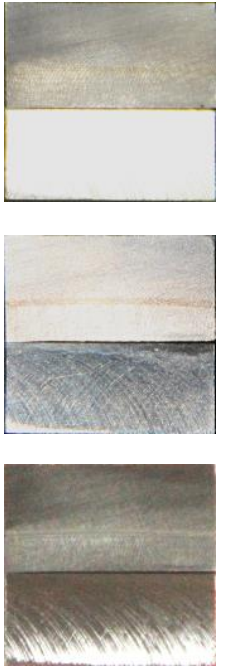

Stellite-welded
Fig. 6 Water erosion photos at different moments for testing material specimen

As shown in Fig. 6, in the early stage, the water erosion traces consist of a series of discrete micro pits. Then these pits are connected to each other and the erosion grooves form and expand gradually. As can be seen above, the size of water erosion grooves is the largest. At the same time, the erosion traces for stellitewelded specimen are less obvious compared with those of other two specimens, which shows that stellite-welded specimen has the best resistance of water erosion the present study.

The mass loss per unit area can be used to measure the extent of water erosion for the testing material. During the experiment, mass weighing is conducted 6 times and the mass loss curves are shown in Fig. 7 to Fig. 9.

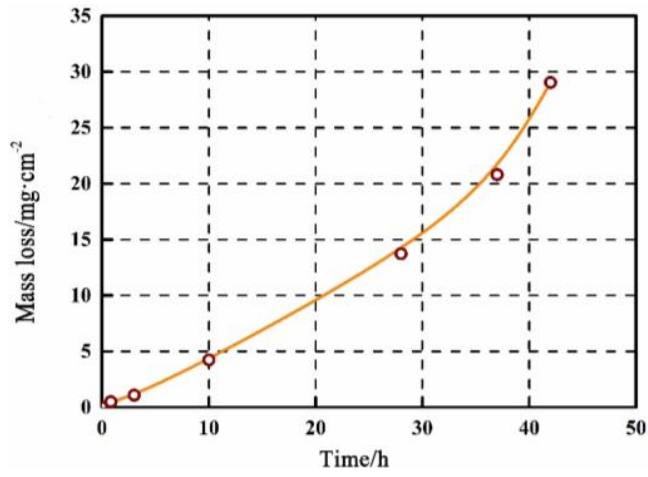

Fig. 7 Mass loss curve of water erosion with base material specimen

It can be seen that the water erosion occurs when the experiment starts. The water erosion rate is relatively constant, which should be regarded as a straight line theoretically. However, after 30 hours the slope of the curve begins to rise, and it is found that the pit depth is larger than $400 \mu \mathrm{m}$. This may be because that the heat treatment for the base material specimen is not enough, which results in the stress focus and other defects.

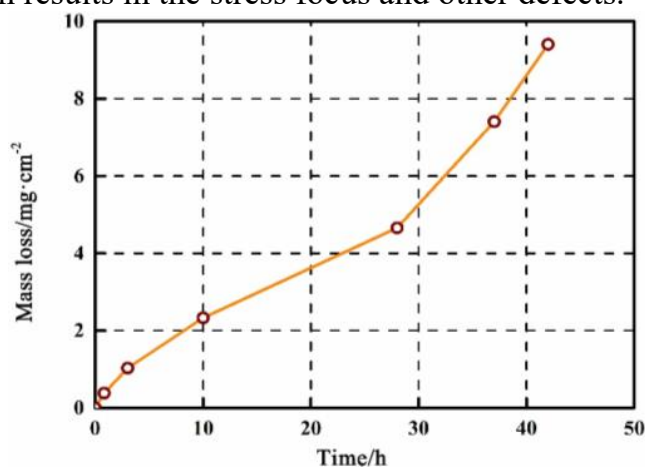

Fig. 8 Mass loss curve of water erosion with high-frequency quenching specimen

The erosion pits appear at the moment of 6 hours for the high-frequency quenching specimen. However, the curve slope during the first 6 hours seems to be much higher than that after the erosion starts, which is mainly because that the high frequency quenching specimen are polished by the high-velocity jets in the early erosion stage. After the moment of 10 hours, the slope of the curves is reduced, which indicates that water erosion pits have reached the hardened layer. The time when the erosion reaches the base material can be estimated as 28 hours in the experiment process from the Fig. 8 because of the rising water erosion rate. 


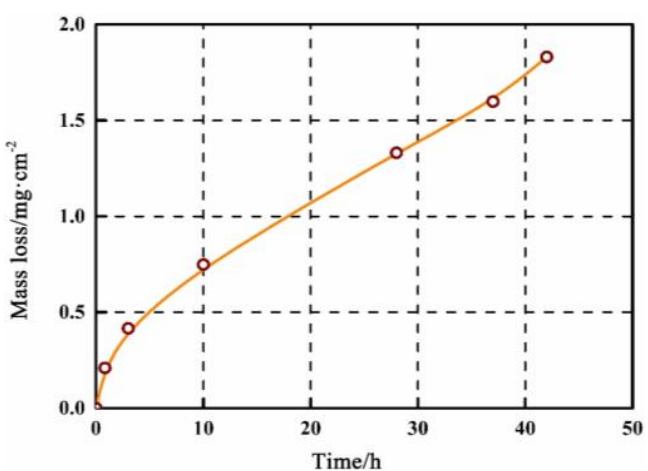

Fig. 9 Mass loss curve of water erosion with stellite-welded specimen

As shown in Fig. 9, the initial slope of the mass loss curve for stellite-welded material specimen is quite large, which is the same with that of the high-frequency quenching specimen. Because the specimen surface is rough and the lateral water jet polishes the target surface, which leads to a great quantity of mass loss. In addition, another excellent characteristic of the stellite-welded specimen is that the mass loss is still little after obvious water erosion. The water erosion rate nearly keeps at a constant value during the whole experiment with the total mass loss of only $1.83 \mathrm{mg} / \mathrm{cm}^{2}$.

In order to observe the changes of water erosion pits, the $2 \mathrm{D}$ microscopic water erosion regions at different moments are shown in Fig. 10.
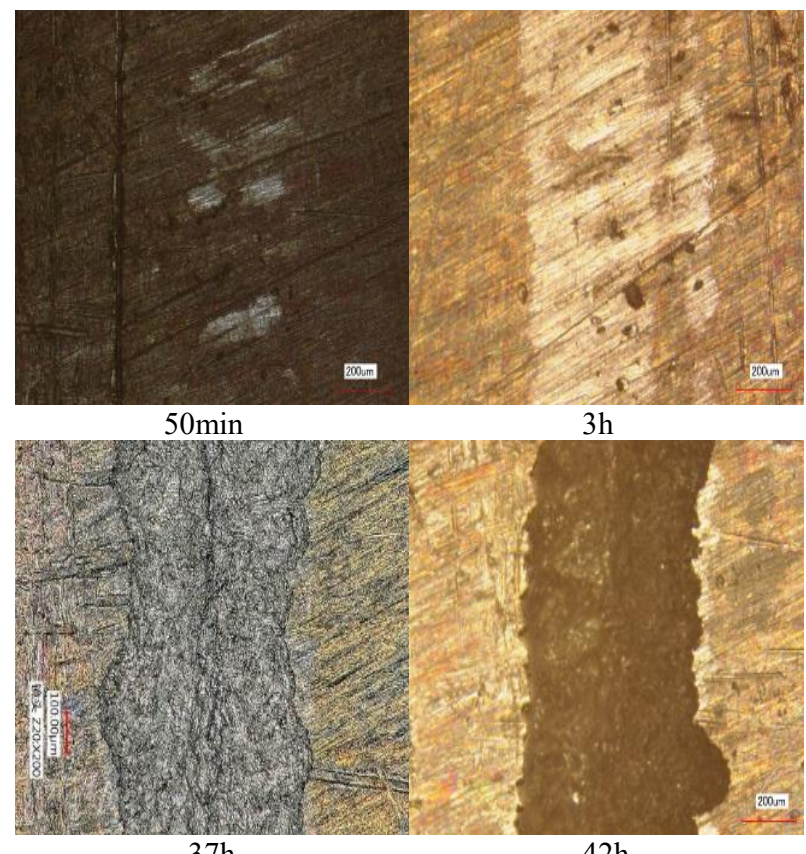

$37 \mathrm{~h}$

$42 \mathrm{~h}$

Fig. 10 2D microscopic water erosion regions at different moments with high-frequency quenching specimen

It is shown from Fig. 6 that the water erosion is not obvious and there are only some friction traces in the first 3 hours. When it reaches to the moment of 50 minutes, the friction traces appear as discrete micro pits. After the moment of 6 hours, water erosion develops faster until the experiment is over. It can be observed within $2 \mathrm{D}$ photos that the pit width nearly remains the same value during the later erosion period.
In order to analyse the water erosion morphology and specific values of erosion pit width and depth, the 3D microscopic morphologies are obtained, shown in Fig. 11.

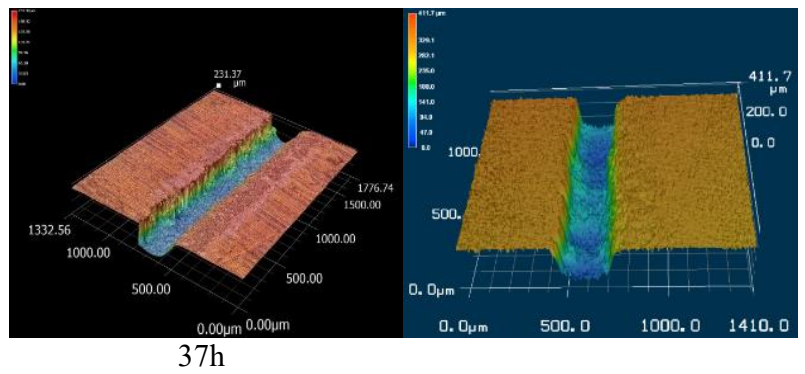

Fig.11 3D water erosion area morphologies at different moments with high frequency quenching specimen

Because no significant water erosion phenomenon occurs within the incipient 6 hours, the 3D pit topography cannot be obtained. Then with the accumulation of impact effect, the water erosion accelerate gradually and pits start to appear. The maximum height differences for the moment of 37 hours and 42 hours are $231 \mu \mathrm{m}$ and $411.70 \mu \mathrm{m}$ respectively.

In order to illustrate the expansion law of water erosion pits, the basic dimensions of the specimen pits are listed in Table 1.

Table 1 Pit sizes at different moments with base material specimen

\begin{tabular}{|c|c|c|c|}
\hline Items & 3hours & 37hours & 42hours \\
\hline $\boldsymbol{D} / \mu \mathrm{m}$ & 42.00 & 382.01 & 445.32 \\
\hline $\boldsymbol{W} / \mu \mathrm{m}$ & 175.90 & 560.00 & 578.00 \\
\hline
\end{tabular}

The pit depth $(\boldsymbol{D})$ of the specimen keeps increasing from the moment of 3 hours to 42 hours. In addition, pit width $(\boldsymbol{W})$ also develops to $578 \mu \mathrm{m}$, which grows much faster than the pit depth. After some time since water erosion occurs, it can be approximately believed that the pit width stops increasing, but the depth gets larger. So it can be easily seen that there is a gradual increase in the depth. However, the pit width nearly remains the same value during the erosion later period.

On the other hand, the density and the surface coating are different for materials treated by different technologies, so it cannot meet the requirements just by comparing the mass loss. Therefore, the volume per unit length should be obtained to make comparisons according to the section dimensions.

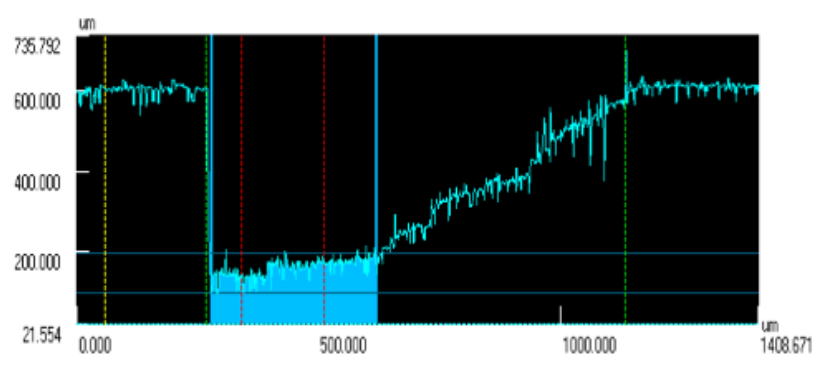

(a) Base material 


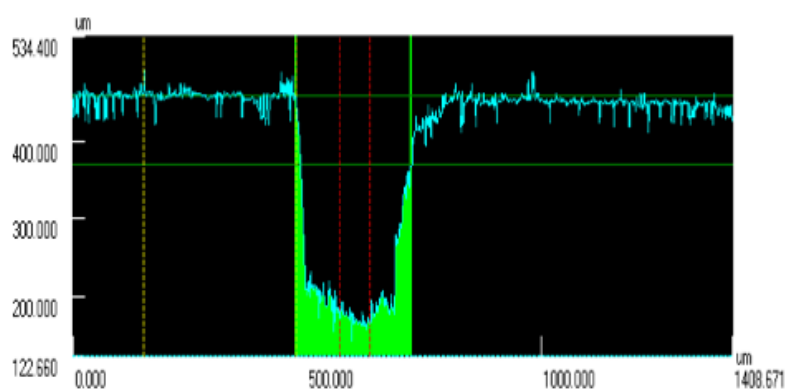

(b) High frequency quenching material

Fig. 12 Section height curves with the testing material

As shown in Fig. 12, the position where the curve trends to go down and the position where the pit area is over are recorded. The integration is conducted between the two regions to obtain the area between the curve and the coordinate axis. The total original area among the section can be obtained according to the average height of the region without water erosion. Then the difference of the two areas is the pit area. The contrast histograms for the pit section dimension of all the specimens are shown in Fig. 13.

The histograms can reflect the huge difference of water erosion resistance performances for different treatment processes. The most serious water erosion appears on the base material specimen, and the pit section area is $0.26313 \mathrm{~mm}^{2}$ while it is $0.06628 \mathrm{~mm}^{2}$ for the high-frequency quenching material specimen, which indicates that after high-frequency quenching, the water erosion resistance performance is strengthened 3.97 times relative to the base material. Compared with the base material specimen, the surface treatment technology of high-frequency quenching improves the surface hardness by forming a hardened layer, so that the water erosion resistance performance gets significantly enhanced. The pit section area of stellite-welded specimen is about $0.00239 \mathrm{~mm}^{2}$, which indicates that the water erosion resistance of stellite-welded specimen is 110 times and 28 times stronger than the base material specimen and the high frequency quenching material specimen respectively.

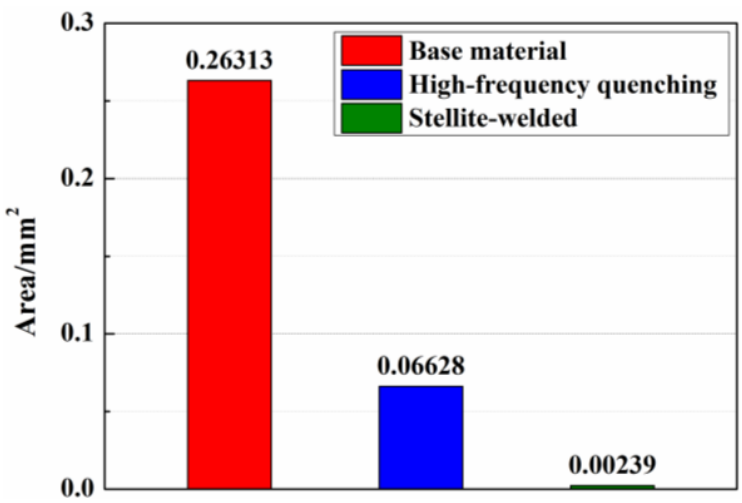

Fig. 13 Water erosion pit area of the testing material specimens

In the present study, the hardened layer of the high frequency quenching material specimen is probably equal to the thickness of the stellite alloy. It is also found that stellite-welded specimen has not only high hardness, but also strong toughness. The time when water erosion pits for stellite-welded specimen appear is just 4 hours later than that of the high-frequency quenching material specimen, however the total mass loss for stellite-welded specimen is extremely small in the 38 hours left. At the same time, the hardened layer of the high-frequency quenching material specimen has been penetrated and water jet has reached the base material, which results in a large of mass and volume loss.

\section{Conclusions}

The rotary water erosion experiment platform, which is designed and established independently, is applied for the water erosion experimental analysis of the base material specimen, high-frequency quenching material specimen and stellite-welded specimen. The main conclusions are as follows:

1) The water erosion experiment results for three kinds of specimens during 42 hours are obtained and analysed in detail. A detailed analysis of the water erosion characteristics of each material of each stage and the curves of mass loss are obtained. The 2D and 3D morphologies of water erosion pits are acquired.

2) The depth and width data are gained according to erosion pit section curves. It is important to find that the width develops faster than the depth, which indicates that the cutting and scouring effect of lateral jet caused by impact is the main cause of the water erosion phenomenon.

3) It is found that the water erosion resistance performance of stellite-welded specimen is 110 times and 28 times stronger than that of the base material specimen and the high frequency quenching material specimen respectively by contrast.

\section{References}

1. Honegger, E. Brown Boveri Rev., 12: 263 (1924)

2. Hoff G, Langbein G, Rieger H. Erosion by Cavitation or Impingement, 408, 42-69 ( 1967)

3. Ripken J F. University of Minnesota, St. Anthony Falls Hydraulic Laboratory (1962)

4. Elliott D E, Marriott J B, Smith A. ASTM Spec. Tech. Publ, 474, 127-161 (1970)

5. Rudy S L, Thiruvengadam A. NASA CR-1288 (1971)

6. Bowden F P, Brunton JH. Proceedings of the Royal Society Series A (1961)

7. Brunton J H. Proceedings of the Royal Society Series A (1966)

8. Jenkins D C, Booker J D, Sweed J W. Aeronautical Research Council R\&M No.3203 (1961)

9. Toshiyuki S, Masao W, Minori S, et al. Fluid Dynamics Research, 40(7-8): 627-636.(2008) 